Tropical Journal of Pharmaceutical Research December 2018; 17 (12): 2393-2398

ISSN: 1596-5996 (print); 1596-9827 (electronic)

(1) Pharmacotherapy Group, Faculty of Pharmacy, University of Benin, Benin City, 300001 Nigeria.

Available online at http://www.tjpr.org

Original Research Article

http://dx.doi.org/10.4314/tjpr.v17i12.12

\title{
Activating transcription factor 3 enhances chemosensitivity of dichloroacetic acid via p53 pathway in cervical squamous epithelial cancer cells
}

\author{
Zuohelaguli Mutalifu, Gulimire Buranjiang, Hua Jin* \\ Department of Gynecological Radiation Therapy II Ward, The 3rd Affiliated Teaching Hospital of Xinjiang Medical University ( \\ Affiliated Cancer Hospital), Urumqi, Xinjiang 830011, China
}

*For correspondence: Email: jinhuaxinjmd@163.com; Tel: +86-13095003608

Sent for review: 10 October 2018

Revised accepted: 28 November 2018

\begin{abstract}
Purpose: To investigate the effect of activating transcription factor 3 (ATF) on dichloroacetic acid (DCA) for the treatment of cervical cancer.

Methods: 3-(4,5-Dimethylthiazol-2-yl)-2,5-diphenyltetrazolium bromide (MTT) assay and flow cytometry assays were first used to determine the effect of DCA treatment on SW756 cells. Next, western blotting was performed to test apoptotic markers and activating transcription factor 3 (ATF3) expression. MTT and flow cytometry assays were conducted to test the effect of ATF3 on the viability and apoptosis of cervical cancer cells. Finally, western blotting, quantitative real-time polymerase chain reaction (qRT$P C R$ ), and flow cytometry assays were used to examine the causality between ATF3 and P53.

Results: The expression of ATF3 was significantly upregulated $(p<0.001)$ in cervical cancer cells treated with DCA. ATF3 overexpression consolidated the suppressive effect of DCA on cell proliferation and induced apoptosis $(p<0.001)$, suggesting that tumor protein 53 (P53), a tumor suppressor, was responsible for ATF3-mediated anti-tumorigenesis in DCA-treated cervical cancer.

Conclusion: These results indicate that ATF3/P53 signaling is critical to treating cervical cancer with $D C A$ and provides new insights into cervical cancer diagnosis, treatment and prognosis.
\end{abstract}

Keywords: Cervical squamous epithelial cancer, Activating transcription factor, Tumor protein 53 (P53), Tumor suppressor, Dichloroacetic acid

\begin{abstract}
This is an Open Access article that uses a funding model which does not charge readers or their institutions for access and distributed under the terms of the Creative Commons Attribution License (http://creativecommons.org/licenses/by/4.0) and the Budapest Open Access Initiative (http://www.budapestopenaccessinitiative.org/read), which permit unrestricted use, distribution, and reproduction in any medium, provided the original work is properly credited.

Tropical Journal of Pharmaceutical Research is indexed by Science Citation Index (SciSearch), Scopus, International Pharmaceutical Abstract, Chemical Abstracts, Embase, Index Copernicus, EBSCO, African Index Medicus, JournalSeek, Journal Citation Reports/Science Edition, Directory of Open Access Journals (DOAJ), African Journal Online, Bioline International, Open-J-Gate and Pharmacy Abstracts
\end{abstract}

\section{INTRODUCTION}

Cervical cancer, including squamous cell carcinoma and adenocarcinoma, results from the transformation of normal cervix epithelial cells into malignant cancer cells $[1,2]$. Several factors such as human papilloma virus (HPV) infection, oral contraceptives, and tobacco smoke are implicated in cervical cancer development [3].
Among these factors, HPV infection is the most consequential, with an estimated $85 \%$ of cervical cancer cases triggered by the infection [4-6]. The HPV vaccine protects against HPV infection and reduces the risk of cervical cancer. Treatment options for patients with cervical cancer are traditional therapeutic regimens, surgery, radiation therapy, and chemotherapy [7-9]. 
Dichloroacetic acid (DCA), an analog of acetic acid, has been shown to suppress tumor growth in many preliminary studies [10]. However, its underlying mechanism of action in cervical cancer remains unclear. Recently, Wang et al. proposed that activating transcription factor 3 (ATF3) may disturb the interaction of E6 and E6AP and further suppress tumor formation via activating P53 pathway [11]. Therefore, this study aimed to determine the potential function of ATF3 in cervical cancer after DCA treatment. As a transcription factor, ATF3 belongs to the ATF/CREB family of transcription factors [12-14]. In cancers, ATF3 plays a distinct role. Some investigators revealed that ATF3 expressed by non-cancer host cells promotes breast cancer metastasis [15]. Others indicated that ATF3 activates P53 and eventually defends against HPV-induced cervical cancer [11].

\section{EXPERIMENTAL}

\section{Cell culture}

Human cervical squamous epithelial cancer cells, SW756, were purchased from the Bena Culture Collection Co., Ltd (Jiangsu, China). In brief, the SW756 cell medium contained Dulbecco's modified Eagle's medium (DMEM). In addition, $10 \%$ fetal bovine serum and $1 \%$ penicillin/streptomycin were added (Gibco, Rockville, MD, USA) for good culture condition. All cell cultures were incubated in a humidified atmosphere containing $5 \% \mathrm{CO}_{2}$.

\section{DCA consumption}

Dichloroacetic acid (Sigma, USA) at different concentrations $(0,20,40$ and $60 \mathrm{nM})$ was added to the SW756 cells at $80 \%$ confluence. The cells were incubated for 24 or $48 \mathrm{~h}$. Finally, the cells were collected for ATF3 examination and functional assays.

\section{RNA extraction and real-time PCR analysis}

mirVana miRNA kit (Takara, Dalian, China) was used to extract total RNA from the cultured cells. Total RNA was reversed transcribed into cDNA using PrimeScriptRT reagent kit (Takara, Dalian, China). The expression of ATF3 were quantified by real-time PCR mixture assays (Takara). The primers used in this study are presented in the Table 1.

\section{Construction of stable cells with ATF3 overexpression or inhibition}

Human ATF3 and control plasmids, si-ATF3, and si- NC were purchased from Hanbio Co., Ltd. (Shanghai, China). Lentiviral packaging kits (Origene, TR30037) were applied to assess the expression of ATF3. Briefly, before lentivirusmediated transfection, $1 \times 10^{5}$ cells were subcultured into a 24-well plate for $24 \mathrm{~h}$. The next day, $2 \mathrm{ml}$ fresh DMEM medium with 6 $\mathrm{mg} / \mathrm{mL}$ polybrene was added to the wells and then cultured at $37^{\circ} \mathrm{C}$. After $4 \mathrm{~h}$, an additional 2 $\mathrm{mL}$ fresh DMEM medium was added to the wells, followed by another $24 \mathrm{~h}$ of incubation. Finally, western blotting, immunostaining, or fluorescence-activated cell sorting assays were used to test the expression of target mRNA.

\section{MTT assay}

An MTT assay kit (Thermo Fisher Scientific, USA) was used to assess the viability of SW756 cells infected with ATF3 or si-ATF3. In brief, 20 $\mu \mathrm{L}$ MTT was added to each well and incubated the cells at $37^{\circ} \mathrm{C}$ for $2 \mathrm{~h}$. Then, the medium was aspirated the medium and added $100 \mu \mathrm{L}$ dimethyl sulfoxide to dissolve the formazan crystals. A microplate reader was used to determine the absorbance of the wells at $\mathbf{5 7 0}$ $\mathrm{nm}$.

Western blot. Expression of ATF3 and markers associated with p53 signaling were determined by western blot. Briefly, the lysate of SW756 cells was prepared with radioimmunoprecipitation assay buffer and quantified the protein using a BCA protein assay kit (CWBIO, CW0014, China). Following primary antibodies were used for detecting the expression levels of corresponding proteins: rat anti-ATF3 (1:1000, Santa Cruz Biotechnology, Inc. Santa Cruz, CA, USA), rat anti-p53, and rabbit anti-BAX (1:800, Santa Cruz Biotechnology, Inc. Santa Cruz, CA, USA). Secondary antibodies conjugated with a horseradish peroxidase label were applied for the expression of ATF3, P53, and BAX test using a chemiluminescence reagent. Human $\beta$-actin was used as the loading control.

Table 1: Primer sequences for qRT-PCR

\begin{tabular}{ll}
\hline Primer & Sequence 5' $>$ 3' \\
\hline ATF3-forward & TCTGGAACCAGACAGCACCT \\
ATF3-reverse & GTGCTGGACTGCTGGAAAGT \\
GAPDH-forward & GGAGCGAGATCCCTCCAAAAT \\
GAPDH-reverse & GGCTGTTGTCATACTTCTCATGG \\
\hline
\end{tabular}




\section{Apoptosis assay}

Apoptosis of SW756 cells was determined using an apoptosis assay kit (ab39674, Abcam, USA). In brief, we first harvested $1 \times 10^{6}$ cells in some experiments. Drug-treated cells were washed with phosphate-buffered saline three times and then resuspended in buffer $\mathrm{A}(500 \mu \mathrm{L})$. Finally, SW756 cervical cancer cells were added to $5 \mu \mathrm{L}$ annexin V/FITC and $1 \mu \mathrm{L}$ propidium iodide. A flow cytometer (BD Biosciences, USA) was used to quantify the proportion of apoptotic cells.

\section{Statistical analysis}

Data are expressed as mean \pm standard deviation. Statistical analysis was performed using Student's t-test or one-way analysis of variance followed by the least significant difference post-hoc test via SPSS 16.0 (SPSS Science, Chicago, IL). Differences with $p$ values less than 0.05 were considered statistically significant.

\section{RESULTS}

DCA decreased the viability of cervical cancer cells

First SW756 cell viability and apoptosis was examined after treatment with DCA. As shown in Figure $1 \mathrm{~A}, \mathrm{DCA}$ significantly reduced the viability of cervical cancer cells in a dose-dependent manner. In addition, the results of the apoptosis assay further demonstrated that DCA promote cancer cell apoptosis in dose-dependent manner (Figure 1 B). The expression of apoptosisassociated proteins, caspase- 3 and poly (ADPribose) polymerase (PARP), were upregulated (Figure $1 \mathrm{C}$ ), indicating a pro-apoptotic role of DCA in cervical cancer cells.

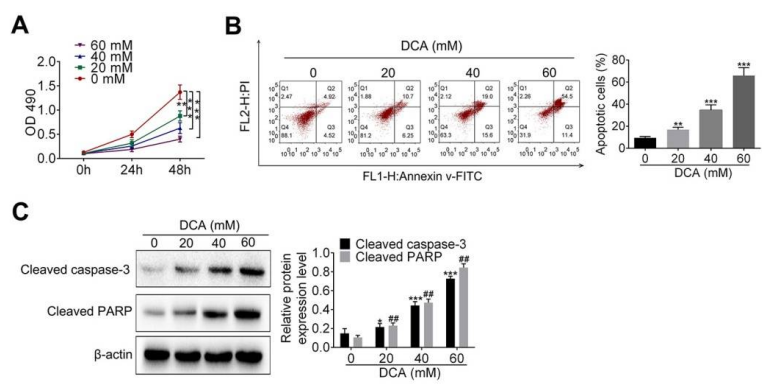

Figure 1: DCA-induced apoptosis in cervical cancer cells. (A) Results of the MTT assays revealed that DCA reduce the viability of cervical cancer cells in a dose-dependent manner. (B) At higher DCA concentrations, higher proportions of apoptotic SW756 cells were observed. (C) DCA facilitated the expression of apoptosis-associated cleaved-caspase 3 and cleaved PARP. ${ }^{* *} P<0.01,{ }^{* * *} p<0.001$ vs. control
ATF3 increased after treatment of DCA in cervical cancer cells

Next, the expressional changes in DCA-treated cervical cancer cells was examined. Notably, the level of ATF3 was observed to be significantly upregulated upon DCA challenge. To verify these results, qRT-PCR and western blotting was performed, and the results indicated that ATF3 expression was upregulated in SW756 cells after treatment with DCA (Figure $2 \mathrm{~A}, \mathrm{~B}$ ). Moreover, this effect was greater at higher DCA concentrations or longer exposure time.

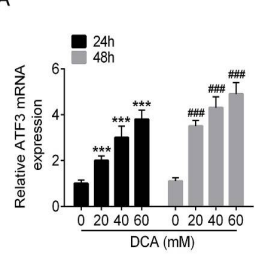

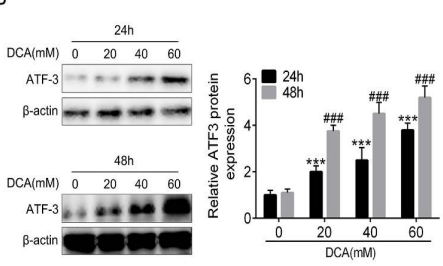

Figure 2: ATF3 expression significantly increased in SW756 cells treated with DCA. (A, B) Results of qRTPCR and western blotting showed that ATF3 was significantly increased by DCA treatment in a timeand dose-dependent manner. (C) DCA inhibited SW756 cell proliferation. (D, E) High doses of DCA promoted SW756 cell apoptosis; ${ }^{* * *} p<0.001$ vs. control at $24 \mathrm{~h}$. \#\#\# $p<0.001$ vs. control at $48 \mathrm{~h}$

\section{Inhibition of ATF3 reversed the effect of DCA on cervical cancer malignancy}

To test the hypothesis that ATF3 inhibition promoted cervical cancer malignancy, stable cervical cancer cells infected with siATF3 was established (Figure 3 A). As expected, after treatment with DCA, ATF3 inhibition promoted malignant proliferation in cervical cancer cells (Figure $3 \mathrm{~B}$ ) and reversed the apoptotic effect of DCA in SW756 cells (Figure $3 \mathrm{C}$ ). The results of western blotting also demonstrated that apoptotic markers, such as cleaved-caspase-3 and cleaved PARP, were decreased after ATF3 inhibition (Figure $3 \mathrm{D}$ ).

Overexpression of ATF3 suppressed malignancy of cervical cancer after treatment with DCA

To further assess the effect of ATF3 on DCAtreated SW756 cells, ATF3 was stably overexpressed in SW756 cells (Figure 4 A), the results showed that the combined utilization of ATF3 and DCA significantly decreased the viability of SW756 cells (data not shown). Overexpression of ATF3 markedly augmented P53/BAX/PUMA signaling pathway, which is important in regulating cell apoptosis. 


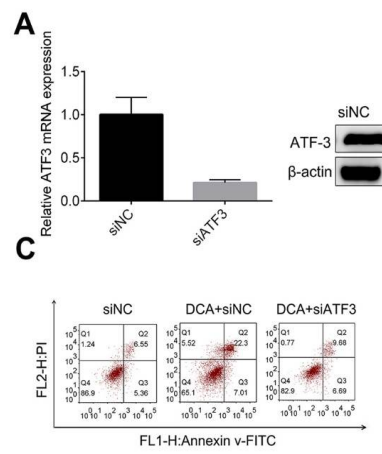

B
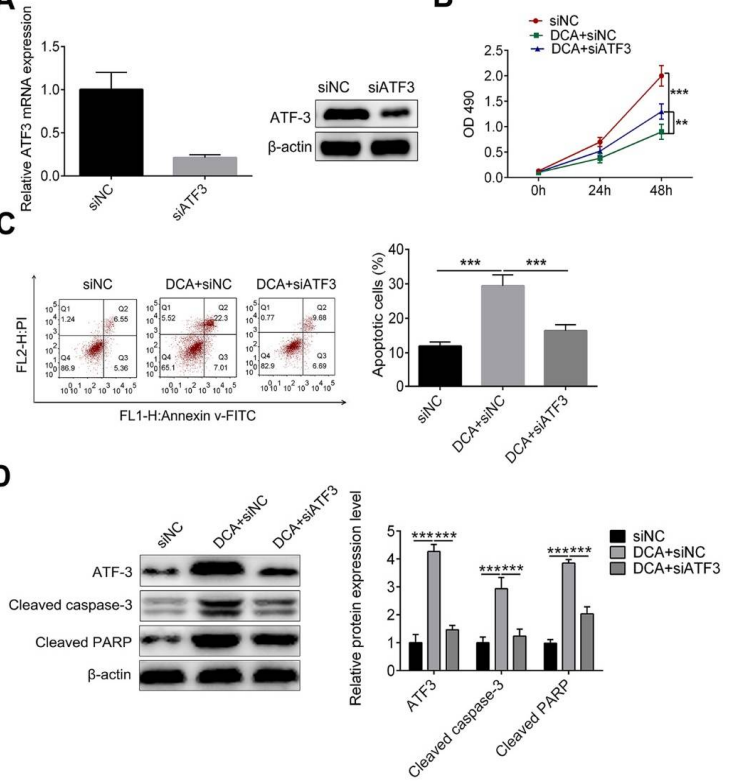

Figure 3: ATF3 inhibition reversed the effects of DCA on SW756 cancer cells. (A) Results of qRT-PCR and western blotting showed that stable cell lines with ATF3 inhibition were successfully established. (B) After treatment with DCA in SW756 cells, ATF3 inhibition can facilitate cancer cell proliferation. (C) ATF3 inhibition decreased the proportion of apoptotic cancer cells. (D) ATF3 inhibition downregulated the expression of cleaved-caspase 3 and cleaved PARP, both of which were major elements of the apoptosis signaling pathway in DCA-treated SW756 cells. ${ }^{* \star *} P<$ 0.001 vs. control

In contrast, ATF3 inhibition suppressed P53/BAX/PUMA signaling pathway (Figure $4 \mathrm{~B}$ ). To verify the causality between ATF3 and P53, ATF-3-overexpressed cells were infected by siP53, and the results showed that P53 inhibition in cervical cancer cells reversed the effect caused by ATF3 overexpression (Figure 4 C, D and E). In addition, P53-mediated pro-apoptotic signaling pathway was also inhibited (Figure 4 F).

\section{DISCUSSION}

DCA can be applied as potential therapeutic option in multiple human disorders, such as diabetes mellitus, lipid and lipoprotein disorders, acquired and congenital lactic acidosis, and several solid tumors [17]. Many preliminary studies have revealed that DCA inhibits pyruvate dehydrogenase kinase (PDK) [18], activates pyruvate dehydrogenase (PDC) and oxidative phosphorylation, and inhibits Hif1a expression, thereby facilitating cancer initiation or development [18]. In addition, DCA increases reactive oxygen species production and causes tumor cell apoptosis and restricted cancer cell proliferation [19].

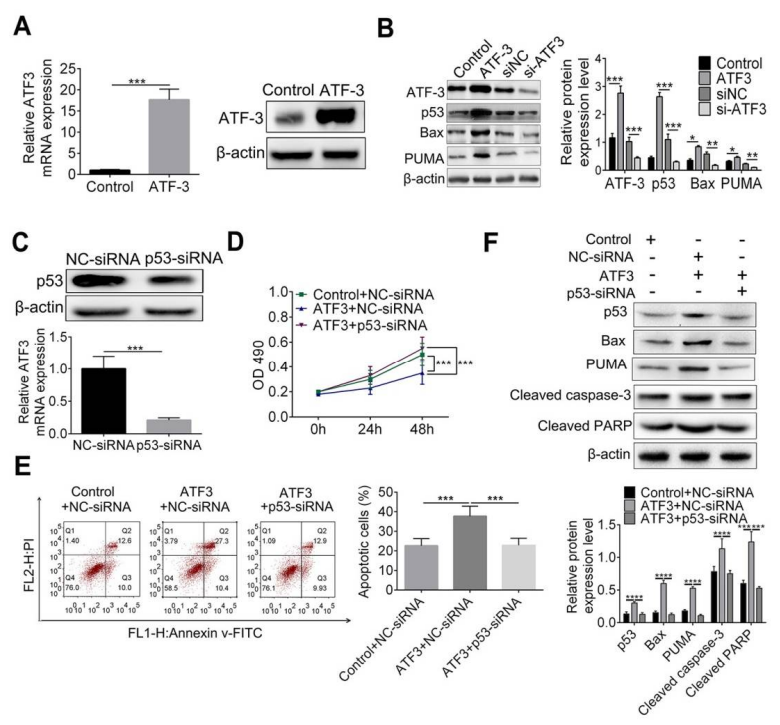

Figure 4: ATF3 prevented DCA-treated malignancy in cervical cancer cells by regulating P53 signaling. (A) qRT-PCR and western blotting results showed that stable cell lines with ATF3 overexpression were successfully established. (B) ATF3 overexpression activated the expression of P53, BAX, and puma and indicated the activation of P53 signaling. However, after ATF3 inhibition, p53-mediated apoptosis was significantly down-regulated. (C, D) P53 inhibition facilitated SW756 cell proliferation with ATF3 overexpression plus DCA exposure. (E) P53 inhibition decreased the proportion of apoptotic SW756 cells after ATF3 expression plus DCA treatment; ${ }^{* *} p<0.01$, ${ }^{* * *} p<0.001$ vs. control

Although phase I clinical trials were applied to test the efficiency of DCA in cancers, there were no relative reports on the effectiveness of DCA for treating cancer [20,21]. Therefore, to date, the underlying mechanisms of DCA's action in cancers remain largely unknown. The inhibitory efficiency of DCA on cervical squamous epithelial cancer cells examined. The results showed that DCA effectively inhibits SW756 cells proliferation and promotes cervical cancer cell apoptosis.

More recent studies have shown that ATF3 plays an important role in cancers. Some investigators have revealed that ATF3 expressed by noncancer host cells promotes breast cancer metastasis [15]. Paradoxically, another scientific paper reported that ATF3 was commonly downregulated and closely associated with the proliferation of clone cancer cells and the tumorigenicity of colorectal cancer cells [22]. However, contradictory results may be caused by distinct pathogenesis of different cancer types. For example, ATF3 was also reported to activate P53 signaling by disrupting the interaction between E6 and E6-associated protein in cervical cancer cells [11]. 
Interestingly, when $\mathrm{Oh}$ and colleagues further studied the function of paclitaxel in cervical cancer cells, it was found that paclitaxel-induced ATF3 caused P21 or BAX transcription. Eventually, overexpression of ATF3 enhanced TAP73b transactivation and pro-apoptotic activities [16], suggesting that DCA can theoretically elevate ATF3 expression and consequently inhibit cervical cancer malignancy. In this study, DCA treatment elevated ATF3 expression in cervical cancer cells in a dosedependent manner. Furthermore, the combined use of ATF3 and DCA facilitated cancer cells apoptosis and restricted SW756 cells proliferation.

The phenotype of ATF3 in cervical cancer cells led to the question whether ATF3 affect cancer cell proliferation and apoptosis and by what mechanism of action. Previous studies indicated that ATF3 is a common activator of P53 [23]. As a tumor suppressor, and mutant P53 is almost observed in all cancers including cervical cancer. Moreover, P53 is also involved in cell cycle arrest, apoptosis, and senescence [24]. In present study, ATF3 potentiated P53 signaling as evidenced by the increased expression of P53, BAX, and PUMA in ATF3-overexpressed SW756 cells. In addition, P53 inhibition showed inhibitory effects on SW756 cell proliferation and promoted apoptosis.

\section{CONCLUSION}

To the best of our knowledge, this study is the first to report that DCA initially regulates ATF3 expression and further regulates cervical squamous epithelial cancer cell proliferation and apoptosis via P53 signaling. The identification of ATF3 not only provides a predictable marker for cervical squamous epithelial cancer development but also a new druggable loci.

\section{DECLARATIONS}

\section{Conflict of Interest}

No conflict of interest associated with this work.

\section{Contribution of Authors}

We declare that this work was done by the authors named in this article and all liabilities pertaining to claims relating to the content of this article will be borne by the authors. Zuohelaguli Mutalifu designed all the experiments and revised the paper. Gulimire Buranjiang performed the experiments, Hua Jin wrote the paper and final approve.

\section{REFERENCES}

1. Waggoner SE. Cervical cancer. Lancet 2003; 361(9376): 2217-2225.

2. Franco EL, Duartefranco E, Ferenczy A. Cervical cancer: epidemiology, prevention and the role of human papillomavirus infection. CMAJ 2001; 164(7): 10171025.

3. Bosch FX, Muñoz N, de Sanjosé S, Izarzugaza I, Gili M, Viladiu P, Tormo MJ, Moreo P, Ascunce N, Gonzalez $L C$ et al. Risk factors for cervical cancer in Colombia and Spain. Int J Cancer 2010; 52(5): 750-758.

4. Howell-Jones R, Bailey A, Beddows S, Sargent A, de Silva $N$, Wilson $G$, Anton $J$, Nichols $T$, Soldan $K$, Kitchener H. Multi-site study of HPV type-specific prevalence in women with cervical cancer, intraepithelial neoplasia and normal cytology, in England. Brit $J$ Cancer 2010; 103(2): 209-216.

5. Nindl I, Rindfleisch K, Teller K, Schneider A, Dürst $M$. Cervical cancer, HPV 16 E6, variant genotypes, and serology. Lancet 1999; 353(9147): 152-164.

6. Goldie SJ, O'Shea M, Campos NG, Diaz M, Sweet S, Kim SY. HPV, cervical cancer, vaccine. Vaccine 2008; 26(32): 4080-4093.

7. Stewart AJ, Viswanathan AN. Current controversies in high-dose-rate versus low-dose-rate brachytherapy for cervical cancer. Cancer 2010; 107(5): 908-915.

8. Magrina JF, Zanagnolo VL. Robotic surgery for cervical cancer. Yonsei Med J 2008; 49(6): 879-886.

9. Cull A, Cowie VJ, Farquharson DI, Livingstone JR, Smart $G E$, Elton RA. Early stage cervical cancer: psychosocial and sexual outcomes of treatment. Brit $J$ Cancer 1993; 68(6): 1216-1220.

10. Tao L, Yang S, Xie $M$, Kramer $P M$, Pereira $M A$. Hypomethylation and overexpression of $C^{-}$jun, and $C^{-}$ myc, protooncogenes and increased DNA methyltransferase activity in dichloroacetic and trichloroacetic acid-promoted mouse liver tumors. Cancer Lett 2000; 158(2): 185-193.

11. Wang $H$, Mo $P$, Ren $S$, Yan C. Activating transcription factor 3 activates p53 by preventing E6-associated protein from binding to E6. J Biol Chem 2010; 285(17): 13201-13210.

12. Hai $T$, Wolfgang $C D$, Marsee $D K$, Allen AE, Sivaprasad U. ATF3 and stress responses. Gene Expre 1999; 7(6): 321-335.

13. Gilchrist M, Thorsson V, Li B, Rust AG, Korb M, Roach JC, Kennedy K, Hai T, Bolouri H, Aderem A. Systems biology approaches identify ATF3 as a negative regulator of Toll-like receptor 4. Nature 2006; 441(7090): 173-178.

14. Thompson $M, X U D$, Williams BRG. ATF3 transcription factor and its emerging roles in immunity and cancer. Int J Mol Med 2009; 87(11): 1053-1060.

15. Chang YS, Jalgaonkar SP, Middleton JD, Hai T. Stressinducible gene Atf3 in the non-cancer host cells contributes to chemotherapy-exacerbated breast cancer 
metastasis. Proc Natl Acad Sci USA 2017; 114(34): E7159.

16. Oh $Y K$, Lee $H J$, Jeong $M H$, Rhee $M$, Mo JW, Song $E H$, Lim JY, Choi KH, Jo I, Park SI, et al. Role of Activating Transcription Factor 3 on TAp73 Stability and Apoptosis in Paclitaxel-Treated Cervical Cancer Cells. Mol Cancer Res 2008; 6(7): 1232-1249.

17. James MO, Jahn SC, Guo Z, Smeltz MG, Hu Z, Stacpoole PW. Therapeutic applications of dichloroacetate and the role of glutathione transferase zeta-1. Pharmacol Ther 2016; 170: 166-180.

18. Kankotia S, Stacpoole PW. Dichloroacetate and cancer: new home for an orphan drug? Biochim Biophys Acta 2014; 1846(2): 617-629.

19. Berendzen K, Theriaque DW, Shuster J, Stacpoole PW. Therapeutic potential of dichloroacetate for pyruvate dehydrogenase complex deficiency. Mitochondrion. 2006; 6(3): 126-135.

20. Strum SB, Adalsteinsson O, Black RR, Segal D, Peress NL, Waldenfels J. Case report: Sodium dichloroacetate
(DCA) inhibition of the "Warburg Effect" in a human cancer patient: complete response in non-Hodgkin's lymphoma after disease progression with rituximabCHOP. J Bioenerg Biomembr 2013; 45(3): 307-315.

21. Sutendra G, Bonnet $S$, Rochefort G, Haromy A, Folmes $K D$, Lopaschuk GD, Dyck JR, Michelakis ED. Fatty acid oxidation and malonyl-CoA decarboxylase in the vascular remodeling of pulmonary hypertension. Sci Trans/ Med 2010; 2(44): 44ra58.

22. Taniue $K$, Kurimoto A, Takeda $Y$, Nagashima T, OkadaHatakeyama $M$, Katou $Y$, Shirahige K, Akiyama $T$. ASBEL-TCF3 complex is required for the tumorigenicity of colorectal cancer cells. Proc Natl Acad Sci USA 2016; 113(45): 12739-12744.

23. Yan $C$, Boyd DD. ATF3 regulates the stability of p53: a link to cancer. Cell Cycle 2006; 5(9): 926-929.

24. Børresen AL, Helland A, Nesland J, Holm R, Trope C, Kaern J. Papillomaviruses, p53, and cervical cancer. Lancet 1992; 339(8805): 1350-1351. 